\title{
Trends in Exclusive Breastfeeding Practices and Factors Affecting Mothers in Suburbs of Lahore
}

${ }^{1}$ Ammara Kaleem, ${ }^{1}$ Iqbal Azhar Ahmad, ${ }^{2}$ Shumaila Rafique, ${ }^{1}$ Suffura Huma, ${ }^{3}$ Shehla Usman, ${ }^{1}$ Shabbir Ahmad

${ }^{1}$ Department of Pediatric, Azra Naheed Medical College, Lahore

${ }^{2}$ Department of Pediatric Neurology, Children's Hospital, Lahore

${ }^{3}$ Department of Pediatric, Avicenna Medical College, Lahore

\begin{abstract}
Introduction: Breast feeding has no match as a nutritional resource during the first six months for an infant, necessary for the health of both mother and infant. In past, Pakistan had worst breast feeding rates and despite efforts to promote breast feeding, situation is not satisfactory. Aims \& Objectives: Our aim was to determine the frequency of mothers having exclusive breast feeding practices and finding various factors which may affect trends of exclusive breast feeding practices, in rural areas of Lahore. Place and duration of study: This study was done during May 2018 to October 2018 at Chaudhary Muhammad Akram Teaching Hospital. Material \& Methods: In this cross sectional study, 254 mothers were interviewed directly and predesigned questionnaire was filled, through non probability consecutive sampling. Data was analyzed using SPSS 20. Post stratification chi square test was applied. Results: Only 34.3 percent mothers were found to practice exclusive breast feed till 6 months of infant age, 93 percent mothers were of age $<35$ years, mean age 26.6 years and $\mathrm{SD} \pm 4.9$. Only 3.5\% initiate breast feeding within an hour of birth. Chi square test revealed association between exclusive breast feed with insufficient breast milk, initiation time of breast feed and early cessation of breast feed $(p<0.05)$. Conclusion: Declining rates of breast feeding creates an alarming situation and suggests to make more aggressive efforts for promotion of breast feeding the infants.
\end{abstract}

Key words: breast feed, insufficient feed, prlecteal feed.

\section{INTRODUCTION}

It is well recognized that breastfeeding is beneficial for the health of both child and the mother. During infancy and early childhood adequate nutrition is important to ensure full potential growth and development. WHO recommends exclusive breastfeeding for initial six months of life. ${ }^{1}$ Thereafter adequate and safe complementary foods should be added, while continuing the breastfeed for up to two years. ${ }^{1,2}$

Breast feeding pervasiveness decreases with increasing age of the infant ${ }^{3}$. In infants it is related to the low risk of gastrointestinal infection, pneumonia, otitis media and UTI and eventually reduces the burden of inpatient admission. More over in non breastfed infants there is elevated risk of childhood obesity, type1 and type2 diabetes, leukemia and SIDS and low IQ. While for mother breast feeding helps to return her to prepregnancy weight very rapidly with reduced risk of developing type-II diabetes. ${ }^{4}$
Despite the well established importance of exclusive breastfeeding, it is not commonly practiced especially in developing world even in many parts of the developed world. ${ }^{4}$ Millions of lives are lost due to suboptimal breast-feeding in developing countries.

Determinants for exclusive breast feeding, by demographic area, have been recognized such as maternal age, education, income, employment, antenatal care, mode of delivery, pre-lacteal feed, information access, cultural practices, parity, feeding technique and easy availability of formula milk in the market. ${ }^{4}$ The importance of this study is to suggest the need to train or retrain the health professionals regarding promotion of and spreading awareness about the significance of exclusive breastfeeding and to provide the rational for a strategy to promote exclusive breastfeed.

\section{MATERIAL AND METHODS}

This study was designed to determine trends in exclusive breast feeding practices in suburbs of 
Lahore. Secondly, to identify the factors that may act as barrier to practice exclusive breast feeding. The study was conducted in the Department of Paediatrics, Chaudhary Muhammad Akram Teaching and Research Hospital, Raiwand road Lahore taking patients from adjacent small villages (namely Arayian-pind, Arayianmorrh, JiaBhagga, Pajian, kachi-Kothi, Adda Plot, Dubai Chowk, Sher Shah Colony) from May to October 2018.

\section{Study population}

The required sample size was calculated by considering exclusive breast feeding at $37.7 \%$ (by WHO), using open epi calculator in population of Raiwand (855,626: 2017 census) $)^{5}$ keeping 90\% confidence level.

\section{Sampling technique and study design}

Sampling was done by non probability consecutive sampling. This cross sectional study was approved by ethical committee of Azra Naheed medical college Lahore.

\section{Inclusion / Exclusion criteria}

All mothers of ages 18 to 45 years coming to pediatrics department were included in the study, having their younger child less than 2 years of age. The mothers with chronic mental and physical health problems, with special child or child with chronic illness and also with sore nipple or breast abscess were excluded.

\section{Questionnaire}

After taking informed consent, 254 subjects participated in this study. All subjects were interviewed through a pre-structured questionnaire which included duration of exclusive breast feed, age, family size, insufficient breast feed, breast feeding technique, pre-lacteal feed, time of initiation, early cessation of feed. Exclusive breastfeeding is defined as "no other food or drink, not even water, except breast milk for 6 months of life, but allows the infant to receive ORS and nutritional suppliments". ${ }^{4}$ Pre-lacteal feed was defined as the feed given to newborn before first breast feed. 6 "Early initiation" means Initiation of breastfeeding within one hour of birth. "Early cessation of breast-feeding" refers to abandoning breast feed before the child's first birthday ${ }^{7}$. Insufficient breast milk means that mother has or perceives that inadequate supply of breast milk to meet the infants need.

\section{Statistical analysis:}

Data was analyzed using SPSS version 20. For quantitative variables mean/_-S.D was presented and qualitative variable (mode of delivery, breast feeding technique and insufficient breast feed, prelacteal feed, presented as frequency and percentages. Data was cross tabulated with exclusive breast feed in four groups and different variables. Post stratification Chi square test was applied and $\mathrm{P}$ value of $<0.05$ was considered as statistically significant.

\section{RESULTS}

Results regarding frequency of different variables are shown in Table-1.

\begin{tabular}{|l|l|c|c|}
\hline \multicolumn{2}{|c|}{ Total subjects=254 } & $\begin{array}{c}\text { Frequency } \\
\text { (n) }\end{array}$ & $\begin{array}{c}\text { Percent } \\
(\%)\end{array}$ \\
\hline \multirow{3}{*}{ Exclusive breast } & $0-1 \mathrm{~m}$ & 65 & 25.6 \\
feed & $2-5 \mathrm{~m}$ & 82 & 32.3 \\
& $6 \mathrm{~m}$ & 87 & 34.3 \\
& Not at all & 20 & 7.9 \\
\hline \multirow{3}{*}{ Age } & $18-25$ & 115 & 45.3 \\
& $26-35$ & 123 & 48.4 \\
\hline \multirow{2}{*}{ Family size } & $35-45$ & 16 & 6.3 \\
\hline Breast feeding & $1-3$ & 105 & 41.3 \\
technique & $\geq 4$ & 149 & 58.7 \\
\hline \multirow{2}{*}{ Insufficient feed } & Yes & 128 & 50.4 \\
& No & 126 & 49.6 \\
\hline \multirow{2}{*}{ Prelecteal feed } & No & 94 & 37.0 \\
& Yes & 160 & 63.0 \\
\hline \multirow{2}{*}{ Initiation of feed } & No & 207 & 81.5 \\
& $>1 \mathrm{hr}$ & 47 & 18.5 \\
\hline \multirow{2}{*}{ Mode of delivery } & Never & 225 & 3.5 \\
& SVD & 20 & 88.6 \\
\hline \multirow{2}{*}{ Early cessation } & Missing & 179 & 3.9 \\
\hline of breastfeed & Yes & 72 & 28.3 \\
& No & 165 & 65 \\
\hline
\end{tabular}

Table-1: Frequency and Percentages of different variables

The mean age of 254 mothers was 26.6 years and $\mathrm{SD} \pm 4.9$. About $93 \%$ women are under age 35 Data analysis shows that only 34.3 percent mothers are practicing exclusive breast feed till 6 months of infant age.

Cross tabulation with different variables against exclusive breast feed and chi square test revealed some association between exclusive breast feed with insufficient breast milk, initiation time and early cessation of breast feed with p-value $<0.05$.(Table- 2 ) Ninety two percent mothers do breast feed their infants somehow, however $25.6 \%$ stopped during the first month, $32.3 \%$ during $2-5$ month with addition of some other food. The data creating mindfulness is that 20 mothers $(7.9 \%)$ not at all given breast feed to the infants, among those, twelve had large family size. Twelve mothers had SVD, majority $(n=11)$ were not told breast feeding technique and seven had insufficient breast milk. 


\begin{tabular}{|c|c|c|c|c|c|c|}
\hline \multicolumn{7}{|c|}{ Exclusive breast feeding } \\
\hline & $0-1$ month & 2-5 month & 6month & Not at all & Total & $P$-value \\
\hline $\begin{array}{l}\text { Age } \\
18-25 \\
26-35 \\
>35 \\
\text { Total } \\
\end{array}$ & $\begin{array}{l}25(21.7 \%) \\
36(18.6 \%) \\
4(25 \%) \\
65\end{array}$ & $\begin{array}{l}39(33.9 \%) \\
38(19.6 \%) \\
5(31.2 \%) \\
82\end{array}$ & $\begin{array}{l}38(33 \%) \\
42(21.7 \%) \\
7(43.7 \%) \\
87\end{array}$ & $\begin{array}{l}13(11 \%) \\
7(3.6 \%) \\
0 \\
20 \\
\end{array}$ & $\begin{array}{c}115 \\
123 \\
16\end{array}$ & 0.459 \\
\hline $\begin{array}{l}\text { Insufficient bf } \\
\text { Yes } \\
\text { No } \\
\text { Total }\end{array}$ & $\begin{array}{l}36(38.2 \%) \\
29(18.1 \%) \\
65\end{array}$ & $\begin{array}{l}38(40 \%) \\
44(27.5 \%) \\
82\end{array}$ & $\begin{array}{l}13(13.8 \%) \\
74(46.2 \%) \\
87\end{array}$ & $\begin{array}{l}7(7.4) \\
13(8.1 \%) \\
20\end{array}$ & $\begin{array}{c}94 \\
160\end{array}$ & 0.001 \\
\hline $\begin{array}{l}\text { Early cessation } \\
\text { Yes } \\
\text { No } \\
\text { Total } \\
\end{array}$ & $\begin{array}{l}0 \\
31(44.2 \%) \\
34(20.7 \%) \\
65 \\
\end{array}$ & $\begin{array}{l}0 \\
27(38.5 \%) \\
55(33.5 \%) \\
82\end{array}$ & \begin{tabular}{|l|}
0 \\
$12(17.1 \%)$ \\
$75(45.7 \%)$ \\
87 \\
\end{tabular} & $\begin{array}{l}20(100 \%) \\
0 \\
0 \\
20 \\
\end{array}$ & $\begin{array}{c}20 \\
70 \\
164\end{array}$ & 0.001 \\
\hline $\begin{array}{l}\text { Pre-lacteal feed } \\
\text { Yes } \\
\text { No } \\
\text { Total } \\
\end{array}$ & $\begin{array}{l}52(25.1 \%) \\
13(27.6 \%) \\
65\end{array}$ & $\begin{array}{l}63(30.4 \%) \\
19(40.4 \%) \\
82\end{array}$ & $\begin{array}{l}73(35.2 \%) \\
14(29.7 \%) \\
87\end{array}$ & $\begin{array}{l}19(9.1 \%) \\
1(2.1 \%) \\
20\end{array}$ & $\begin{array}{c}207 \\
47\end{array}$ & 0.258 \\
\hline $\begin{array}{l}\text { Initiation time } \\
<1 \mathrm{hr} \\
>1 \mathrm{hr} \\
\text { never } \\
\text { Total } \\
\end{array}$ & $\begin{array}{l}3(33.3 \%) \\
62(27.5 \%) \\
0 \\
65\end{array}$ & $\begin{array}{l}3(33.3 \%) \\
79(35.1 \%) \\
0 \\
82\end{array}$ & $\begin{array}{l}3(33.3 \%) \\
84(37.3 \%) \\
0 \\
87\end{array}$ & $\begin{array}{l}0 \\
0 \\
20(100 \%) \\
20 \\
\end{array}$ & $\begin{array}{c}9 \\
225 \\
20\end{array}$ & 0.001 \\
\hline $\begin{array}{l}\text { Mode of delivery } \\
\text { LSCS } \\
\text { SVD } \\
\text { Total } \\
\end{array}$ & $\begin{array}{l}24(26.9 \%) \\
41(24.8 \%) \\
65\end{array}$ & $\begin{array}{l}26(29.2 \%) \\
56(33.9 \%) \\
82\end{array}$ & $\begin{array}{l}31(34.8 \%) \\
56(33.9 \%) \\
87\end{array}$ & $\begin{array}{l}8(8.9 \%) \\
12(7.2 \%) \\
20\end{array}$ & $\begin{array}{c}89 \\
165\end{array}$ & 0.866 \\
\hline \begin{tabular}{|l|} 
Breast feeding \\
technique education \\
Yes \\
No \\
Total \\
\end{tabular} & $\begin{array}{l}31(24.2 \%) \\
34(26.9 \%) \\
65\end{array}$ & $\begin{array}{l}39(30.4 \%) \\
43(34.1 \%) \\
82\end{array}$ & $\begin{array}{l}49(38.2 \%) \\
38(30.1 \%) \\
87\end{array}$ & $\begin{array}{l}9(14.8 \%) \\
11(8.7 \%) \\
20\end{array}$ & $\begin{array}{l}128 \\
126\end{array}$ & 0.592 \\
\hline
\end{tabular}

Table-2: Cross tabulations between exclusive breast feed and different variable

\section{DISCUSSION}

Exclusive breast feeding till six month of age is most important parameter to prevent malnutrition and promote child health. WHO-UNICEF reported $^{8,9}$ in Pakistan $18 \%$ mothers practice early initiation of the breast feeding and $37.7 \%$ do exclusive breast feeding till six month of age, while in this study just $3.5 \%$ mothers do early initiation of breast feeding and $34.3 \%$ mothers exclusively breast feed till 6 month of age which is much below the recommended exclusive breast feeding standard $(60 \%)$. Mostly (58.7\%) have large family size (> 3 children) Mothers (63\%) have sufficient breast milk for their infants.

In Muheza District Tanga, Aubrey found the rates of exclusive breast feeding increases with age $(37.8 \%$ in 35-49 years $\mathrm{p}=0.034)^{10}$ whereas studies conducted at Ghana ${ }^{11}$ and Kawango ${ }^{12}$ by Mensah et al and Dhakal et al revealed no association of exclusive breast feeding with age. Our results are consistent with Mensah et al and Dhakal et al.

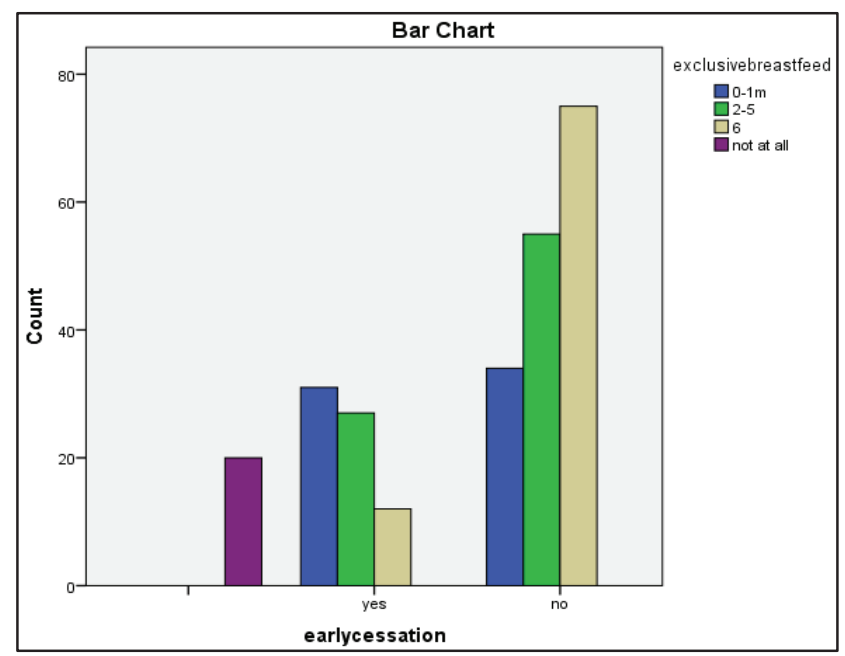

Graph-1: Comparison of exclusive breast feed with early cessation of breast feed

Insufficient breast milk is one of the major inhibitory factors. This study shows that low percentage of mothers feed their infants as compared to mothers having sufficient breast milk 
$(\mathrm{p}<0.5)$. In comparison, data from Quetta ${ }^{13}$ and Sukkur $^{14}$ shows that insufficient milk was a failing factor to continue exclusive breast feeding in $54.8 \%$ and $17.5 \%$ mothers respectively.

In our study, among the mothers who had early cessation of breast feeding, less prevalence of exclusive breast feed is found (17\%). While previously $41.9 \%$ infants had early failure $(<3$ months) and $58.1 \%$ had late failure (4 to 6 months) of breast feed ${ }^{13}$. While about $60 \%$ mothers of United States had cessation of breast feeding earlier than desired period ${ }^{15}$.

Pre-lacteal feed is very common $(81.5 \%)$ among all the infants in this study. It was given in the form of honey or some sweets. However, in Karachi 54\% urban and semi-urban population ${ }^{16}$ while internationally in low and middle income countries $13-76 \%$ infants received pre-lacteal feed and it is negatively associated with exclusive or any breast feeding practices. ${ }^{17}$

In our study, there are low trends for teaching proper breast feeding techniques and early initiation of breast feed. Two third mothers who did not have teaching regarding breast feeding technique could not continue exclusive breast feed upto 6 month of age. This factor definitely improves the breast feeding rates specially in low educated areas. ${ }^{18}$

There is no significant difference between the groups having early initiation of breast feed $(<1 \mathrm{hr})$ or late but significant difference is found between the groups having not initiated breast feed at all and who started breast feed at any time. The mothers who initiated breast feed early majority of them had SVD. In other countries there are higher rates for early initiation of breast feed, more than $50 \%$ in Uganda $^{19} \quad 87 \%$ in Ethopia $^{4}$ and $67 \%$ in Bangladesh. ${ }^{20}$

Otherwise mode of delivery whether LSCS or SVD does not have significant imapact on duration of exclusive breast feeding $(\mathrm{P}=0.866)$ which is consistent with many previous national and international studies..$^{10,21}$

Pakistan has worst breast feeding rates ${ }^{9}$ it is evident that figures were static during the 2006-07 (37.1\%) to $2012-13(37.7 \%)^{22}$ but recently the drop in percentage for exclusive breast feeding and delayed initiation of breast feed are alarming. In Pakistan, NMR is 46 neonates /1000 live births, ${ }^{23}$ infections are top the list causing these deaths which can be prevented with breast feed. Miserably, after knowing all the benefits of breast feed we could not promote the breast feeding rates during the last few years. In future, we can manage it only with the combined efforts of legislation about breast feeding substitutes, improve maternal education regarding benefits and breast feeding technique. We also cannot ignore maternal nutrition and health in the scenario. Our study has certain limitations that the study is recall based, have small sample size, we did not consider the nutritional status of the child and the mother, neither we explored weaning practices.

\section{CONCLUSION}

This study reveals breast feeding rates have declined by $3.4 \%$ presently and only $3.5 \%$ mothers practice early initiation of breast feed. Insufficient breast feed, poor breast feeding technique and prelactael feed are significantly associated with exclusive breast feeding. We need to control all the factors which are hazardous in promoting breast feed at masses so that we can improve public health with prevention of diseases and gain in IQ.

\section{REFERENCES}

1. Exclusive breastfeeding for optimal growth, development and health of infants [Internet]. World Health Organization. 2019 [cited 8 October 2019].

2. Motee A, Jeewon R. Importance of Exclusive Breastfeeding and Complementary Feeding among Infants. Curr ResNutr Food Sci.2014;2(2)

3. Seifu W, Assefa G, Egata G. Prevalence of Exclusive Breast Feeding and its Predictors Among Infants Aged Six Months in Jimma Town, Southwest Ethiopia. J Pediatr Neonatal Care. 2014; 1(3):00017

4. Seid AM, Yesuf ME, Koye DN. Prevalence of Exclusive Breastfeeding Practices and associated factors among mothers in Bahir Dar city, Northwest Ethiopia. Int Breastfeed J. 2013; 8(1):14.

5. En.m.wikipedia.org (2018.) Raiwand Tehsil. [online]

6. El-Gilany A, Abdel-Hady D. Newborn First Feed and Prelacteal Feeds in Mansoura, Egypt. BioMed Research International. 2014; 2014:1-7.

7. Sonko A, Worku A. Prevalence and predictors of exclusive breastfeeding for the first six months of life among women in Halaba special woreda, Southern Nations, Nationalities and Peoples' Region/SNNPR/, Ethiopia: a community based cross-sectional study. Archives of Public Health. 2015; 73(1).

8. Publisher E. WHO EMRO | Breastfeeding gives babies the best possible start in life and breast milk works like a baby's first vaccine | Pakistan-news | Pakistan [Internet]. Emro.who.int. 2018 [cited 3 September 2018]. 
9. UNICEF Pakistan - Media centre - Feeding Babies [Internet]. Unicef.org. 2018 [cited 3 September 2018].

10. Aubrey RM, Michael JM, Damian JD, Sia EM. Factors Affecting Exclusive Breastfeeding among Women in Muheza District Tanga Northeastern Tanzania: A Mixed Method Community Based Study Matern Child Health J. 2016; 20:77-87.

11. Mensah K, Acheampong E, Anokye F, Okyere P, Appiah-Brempong E, Adjei R. Factors influencing the practice of exclusive breastfeeding among nursing mothers in a periurban district of Ghana. BMC Research Notes, 2017: 10(1).

12. Dhakal S, Lee T, Nam E. Exclusive Breastfeeding Practice and Its Association among Mothers of under 5 Children in Kwango District, DR Congo. International Journal of Environmental Research and Public Health, 2017; 14(5), p.455.

13. Farrukh H, Basheer F, Jalil J. Factors Causing Exclusive Breast Feeding Failure In A Pakistani Urban Population VOL 63, No. 3, September 2013.

14. Jamro B, Jamro S, Bhatti R, Kumari R. Experience of exclusive breast feeding in tertiary care hospitals. Med Channel 2011; 17(3): 72-5.

15. Dagher R, McGovern P, Schold J, Randall X. Determinants of breastfeeding initiation and cessation among employed mothers: a prospective cohort study. BMC Pregnancy and Childbirth. 2016; 16(1).

16. Ali S, Ali F, Ayub S, Malick Imam A. Perception and practices of breastfeeding of infants 0-6 months in an urban and a semi-urban community in Pakistan: A cross-sectional study. Journal of the Pakistan Medical Association. 2011; 61(1):99-104.

17. Kavle J, Lacorix E, Dau H, Engmann C. Adressing barrier to exclusive breast feed in low and middle income countries: a systemic review and programmatic implications. Public health Nutrition. 2017; 20(17):3120-3134

18. Tokat MA, Okumus H. Mothers breastfeeding self-efficacy and success: Analysis the effect of education based on improving breastfeeding self-efficacy. J Educ Res Nurs 2013; 10:21-9.

19. Mukunya D, Tumwine J, Nankabirwa V, Ndeezi $\mathrm{G}$, Odongo I, Tumuhamye $\mathrm{J}$ et al. Factors associated with delayed initiation of breastfeeding: a survey in Northern Uganda. Global Health Action. 2017; 10(1):1410975.
20. Karim F, Billah S, Chowdhury M, Zaka N, Manu A, Arifeen $S$ et al. Initiation of breastfeeding within one hour of birth and its determinants among normal vaginal deliveries at primary and secondary health facilities in Bangladesh: A case-observation study. PLOS ONE. 2018; 13(8):e0202508.

21. Sabin A, Manzur F, Adil S. Exclusive breastfeeding practices in working women of Pakistan: A cross sectional study. Pakistan Journal of Medical Sciences. 2017; 33(5).

22. Pakistan has lowest breast feeding rates in South Asia [internet]. thenews.com.pk. 2018 [cited 3 September 2018].

23. PAK-UNICEF Data [internet] UNICEF Data. 2018 [cited 3 September 2018].

\section{The Authors:}

Dr. Ammara Kaleem

Senior Registrar,

Department of Pediatrics,

Azra Naheed Medical College, Lahore.

Prof. Iqbal Azhar Ahmad

Head, Department of Pediatrics,

Azra Naheed Medical College, Lahore.

Dr. Shumaila Rafique

Senior Registrar,

Department of Pediatric Neurology,

Children's Hospital, Lahore.

Dr. Suffura Huma

Assistant Professor,

Department of Pediatrics,

Azra Naheed Medical College, Lahore.

Dr. Shehla Usman

Senior Registrar,

Department of Pediatrics,

Avicenna Medical College, Lahore.

Dr. Shabbir Ahmad

Associate Professor,

Department of Pediatrics,

Azra Naheed Medical College, Lahore.

\section{Corresponding Author:}

Dr. Ammara Kaleem

Senior Registrar,

Department of Pediatrics,

Azra Naheed Medical College, Lahore.

E-mail: ammarakaleem_08@hotmail.com 